\title{
إثكالية التنازع الإيجابي أمام محكمة التنازع في الجزائر
}

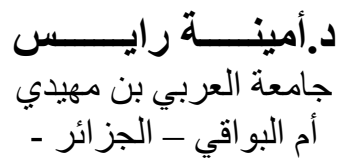

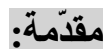

تبنى التعديل الدستوري(1996

نظام الازدواجية القضائية في الجزائر،

ونص لأول مرة على تأسيس هيئات التئات

قضائية؛ من بينها محكمة التنازع التي عهرة

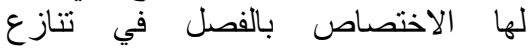

الاختصاص، كما صدر القانون العضوي

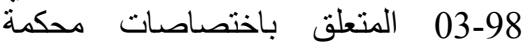

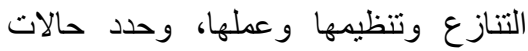

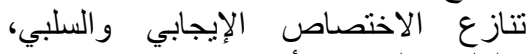

والملفت للانتباه أن تنازع الإنب الاختصاص ولئي

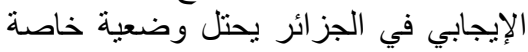

من حيث مفهومه، وشروطائه، مما يثير عديد الإيد

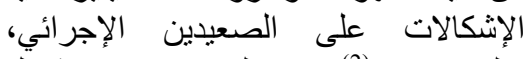

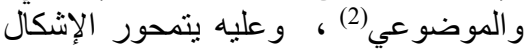

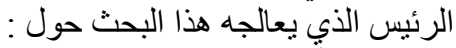

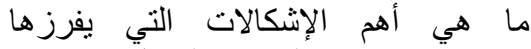

اختصاص محكمة التنازع بالفصل في تنازع الإن

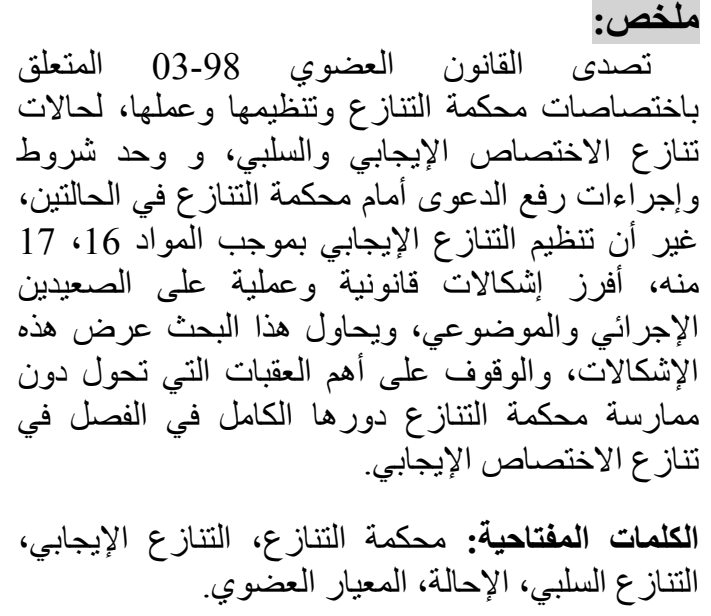

Abstract:

Organic Law 98-03, on the jurisdiction, organization and functioning of the Dispute Tribunal, dealt with cases of conflicts of jurisdiction, both positive and negative. However, the organization of positive conflicts under Articles 16, 17 has created legal and practical problems at the procedural and objective level. This research attempts to present these problems and to uncover the most important obstacles that prevent the Court from fully exercising, and the role in determining the conflict of positive jurisdiction.

Keywords: Court of Conflicts, Positive Conflict, Negative Conflict, Returns, Organic Criterion. 
وللإجابة عن الإشكال السابق، ارتأينا تقسيم الخطة تقسيما ثنائيا على النحو التالي:

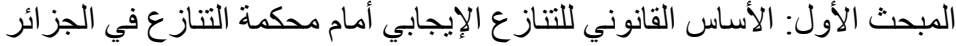

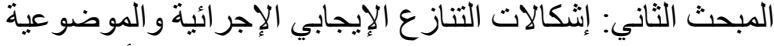

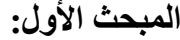

الأساس القانوني للتنازع الإيجابي أمام محكمة التنازع في الجزائر

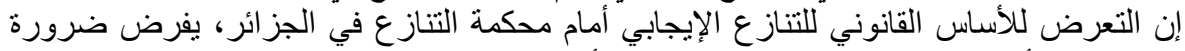

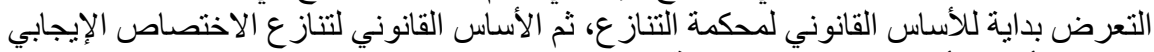

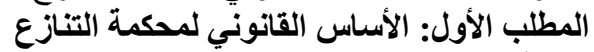

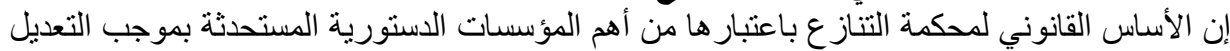

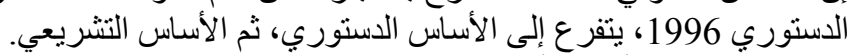
الفرع الأول: الأساس الاستوري الأناسي

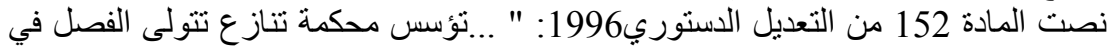

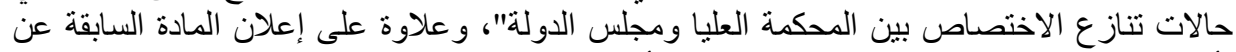

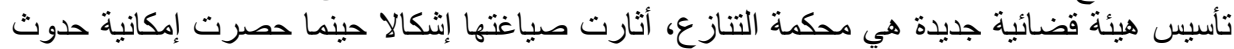

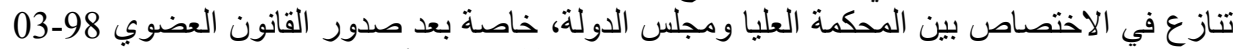

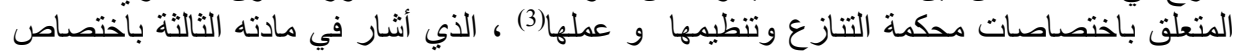

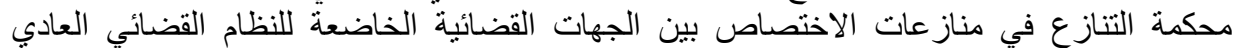

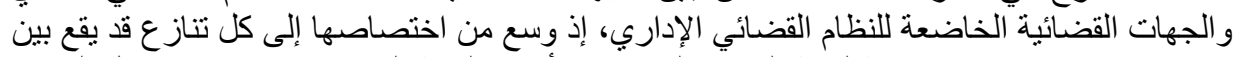

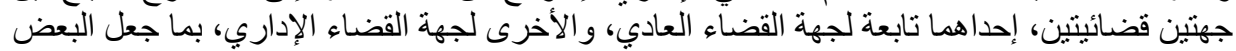

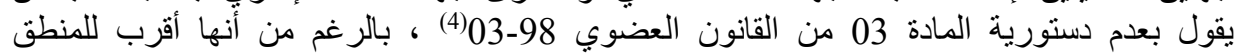

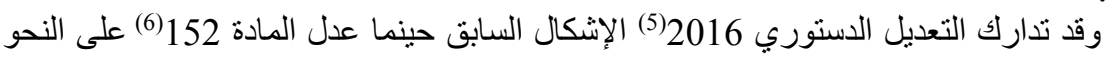

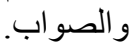

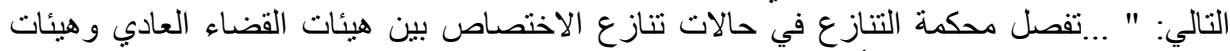

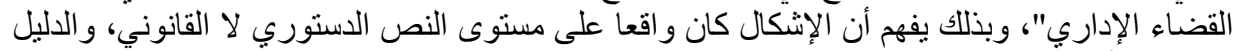

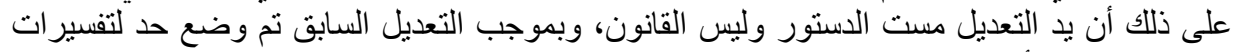

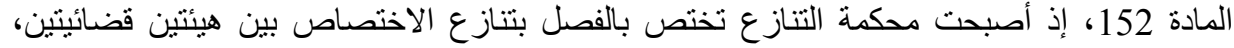

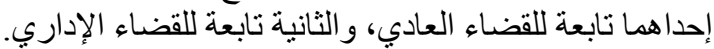
الفرع الثاني: الأساس التشريعي التئية

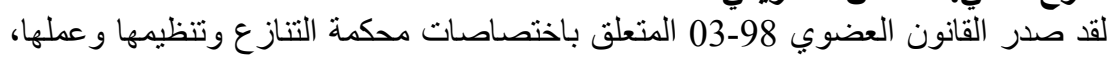

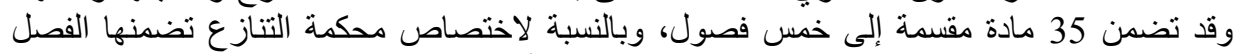

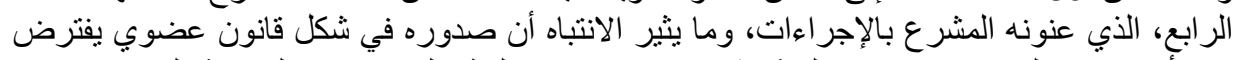

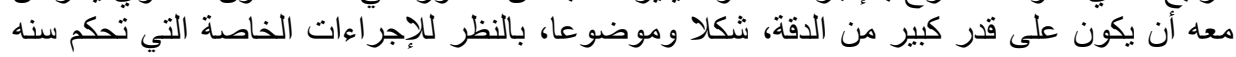

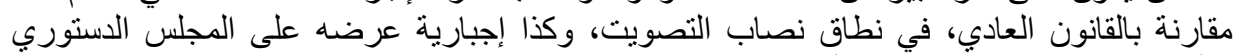

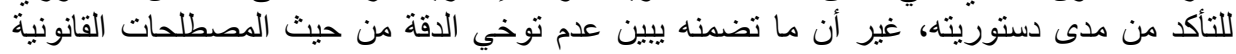

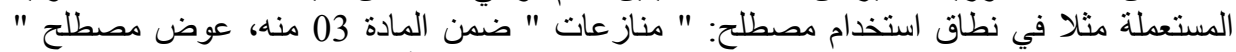

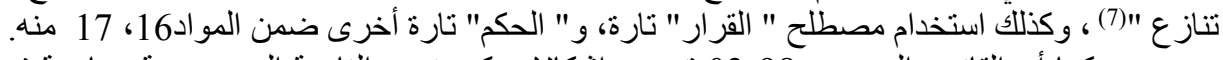

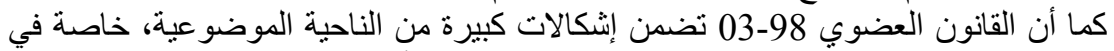

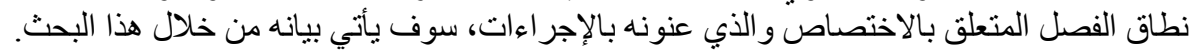

$$
\text { المطلب الثاني: الأساس القانوني لتنازع الاختصاص الإيجابي }
$$

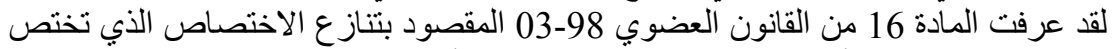

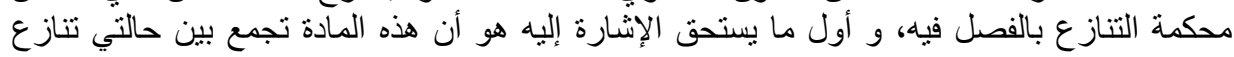


الاختصاص الإيجابي و تنازع الاختصاص السلبي، ومن خلالها فإن المقصود بتنازع الاختصاص

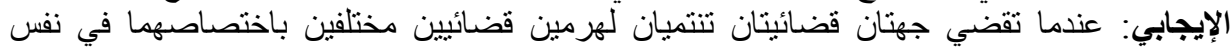

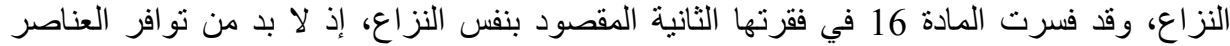

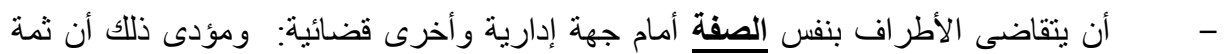

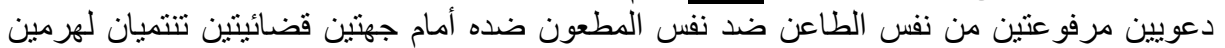

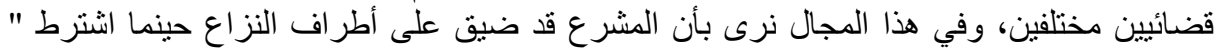

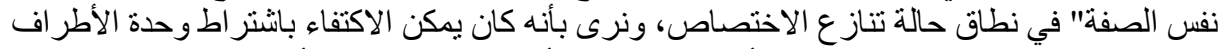

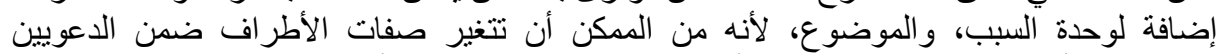

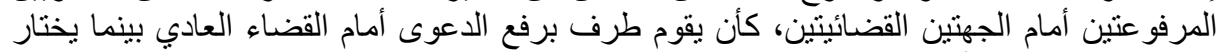
الطرف الثاني رفعها أمام القضاء الإداري.

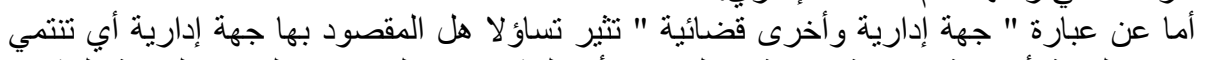

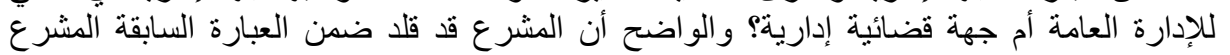

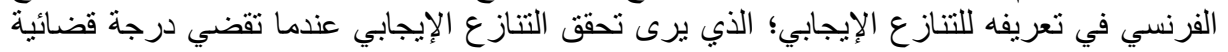

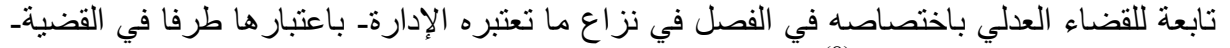

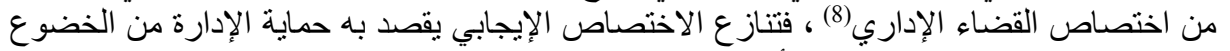

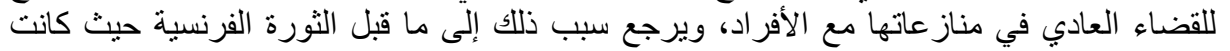

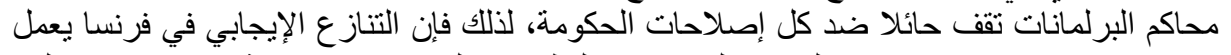

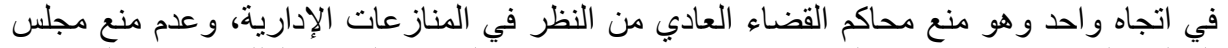

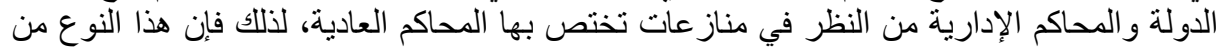

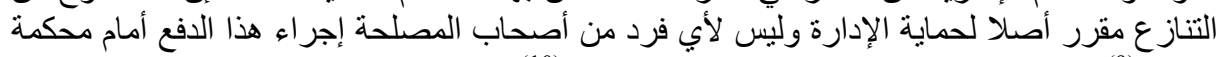

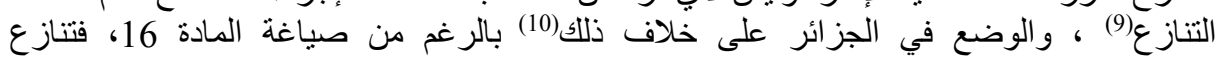

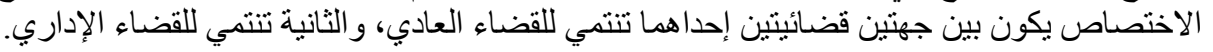

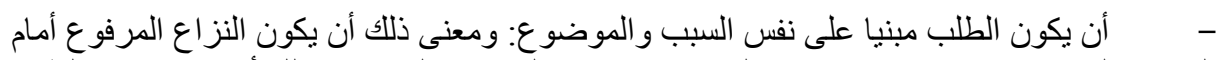

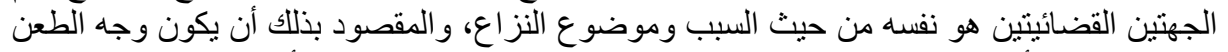

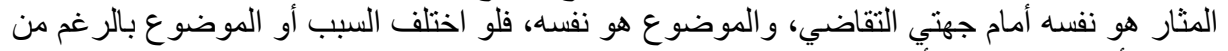

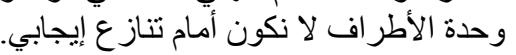

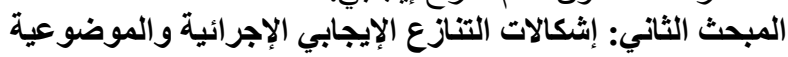

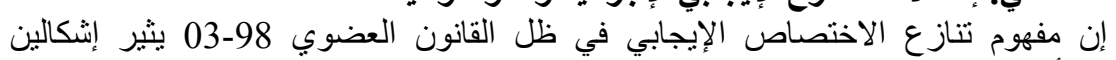

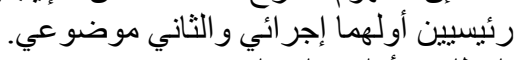
المطلب الأول: على المستوى الإجرائي

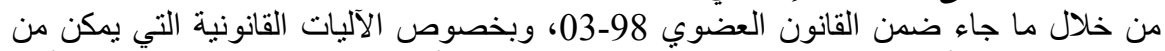

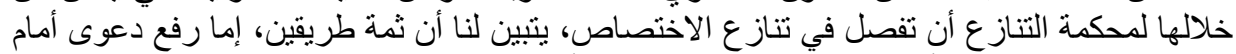
محكمة التتازع من قبل أطر اف النزاع( المادة 17)، أو عن طريق نظام الإحالة من إحدى الجهات المات

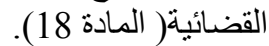

الفرع الأول: رفع الدعوى من قبل أطراف النزاع

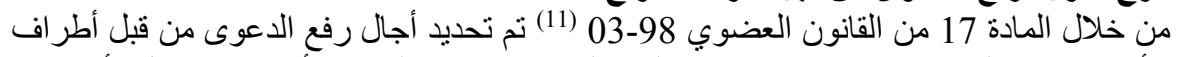

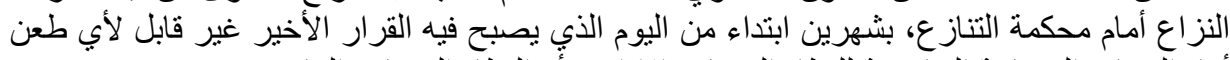

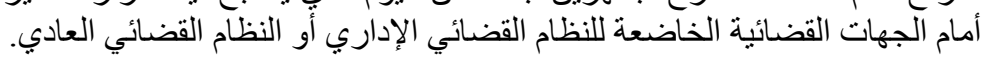

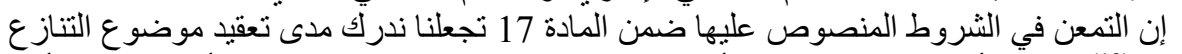

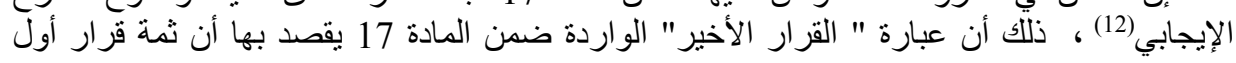


صادر جهة قضائية تنتمي لهرم قضائي معين قضت باختصاصها بالفصل في النزاع، و أصدرت حكما

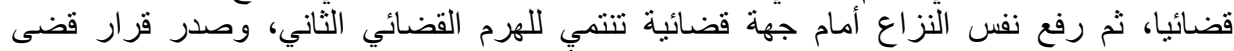

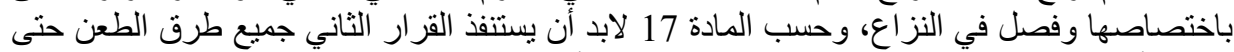

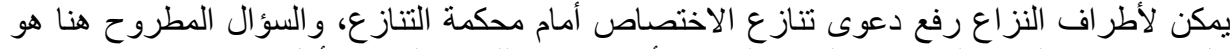

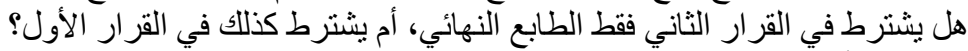

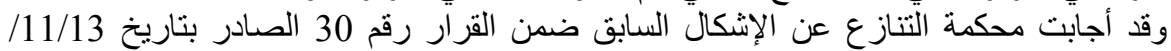

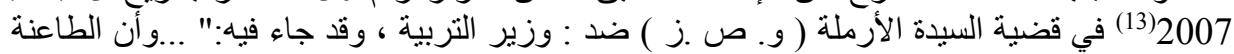
تستند في عريضتها إلى قرارين: قرار صادر من الغرفة الإدارية لمجلس قضاء قسنطينة بتاريخ 2003/06/28 حال فصلها في

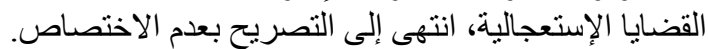

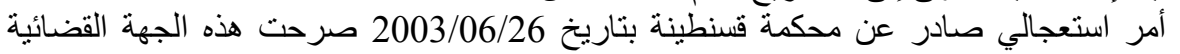
بمو جبه بعدم الاختصاص.

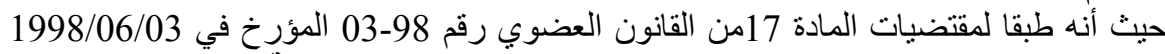
المتعلق باختصاصات محكمة التنازع وتتظيمها و عملها لا تعرض على على محكمة التنازع إلان القرارات "النهائية.... بأن

إن صدور قرارين قضائيين عن جهتين قضائيتين تنتميان لهرمين قضائيين مختلفين لا هائين

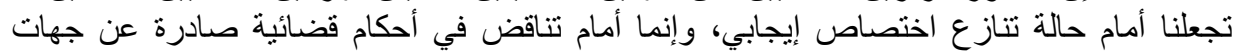

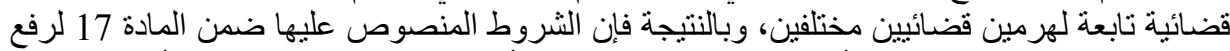

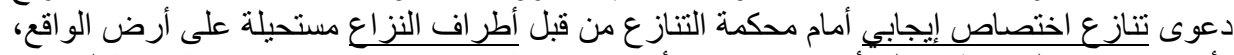

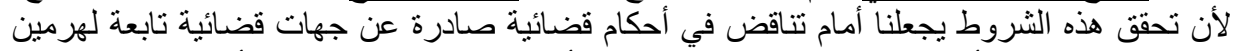

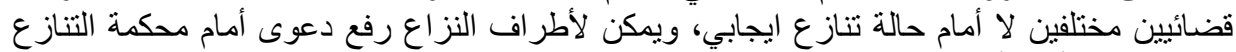

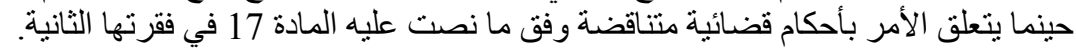

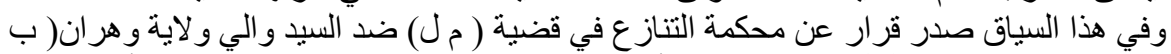

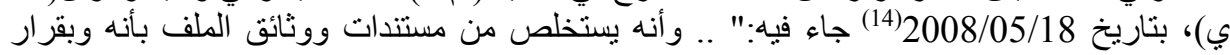

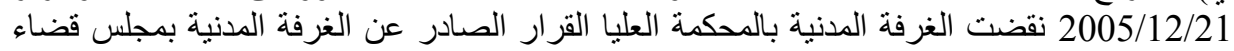

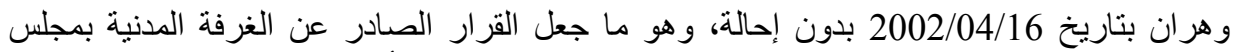

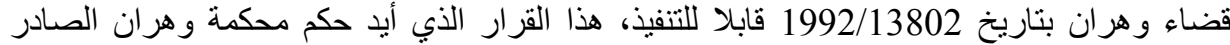

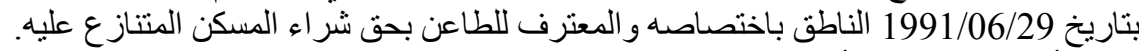

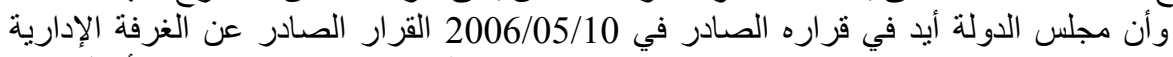

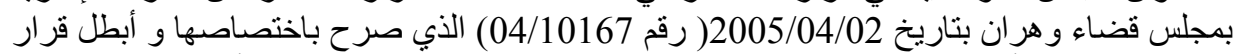

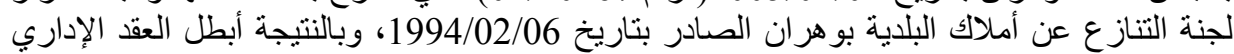

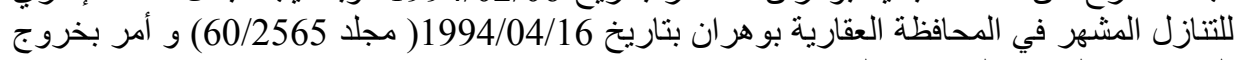
المدعي من المسكن المتناز ع عليه.

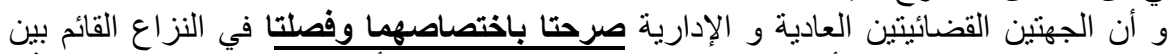

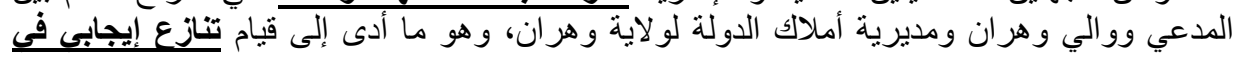
الاختصاصث.

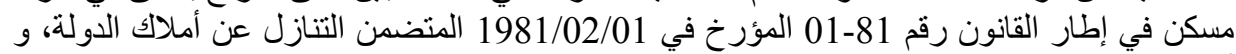

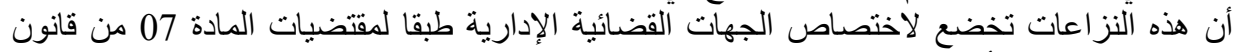

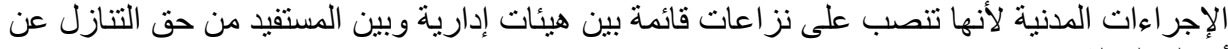


وأن الجهات القضائية العادية قد أخطأت عندما تمسكت باختصاصها و أنه يتعين بالتالي معاينة

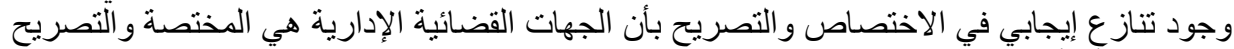

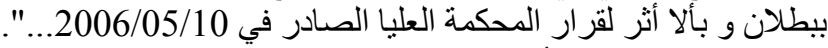

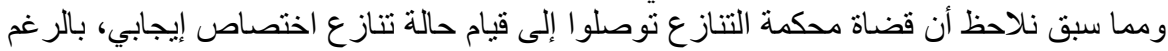

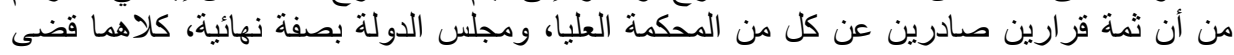

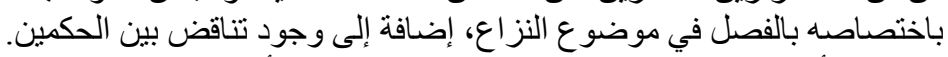

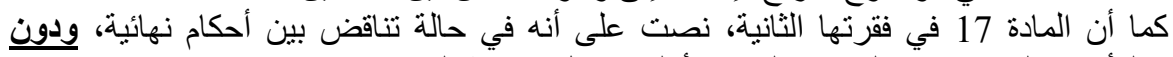

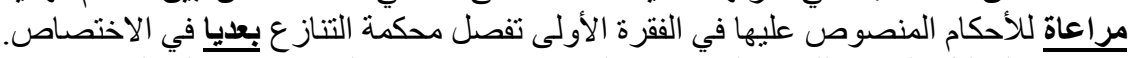

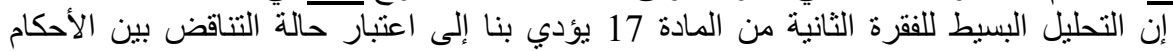

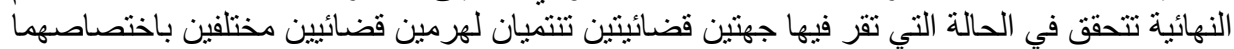

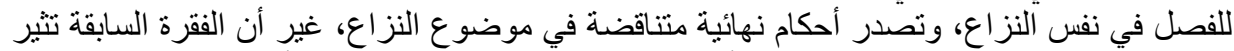

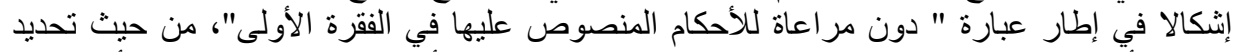

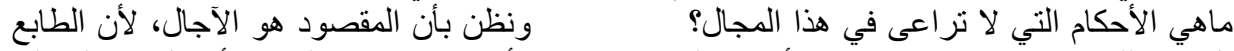

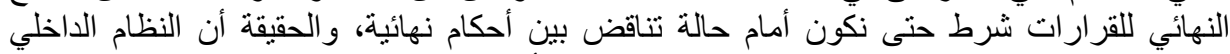

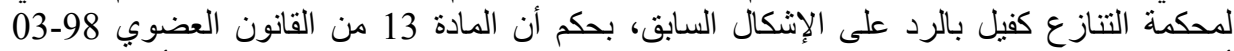

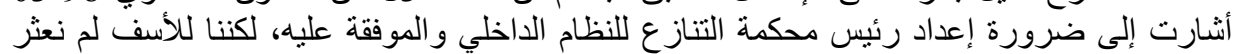

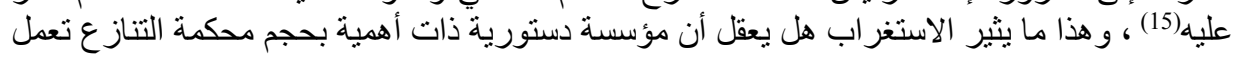

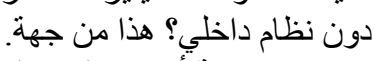

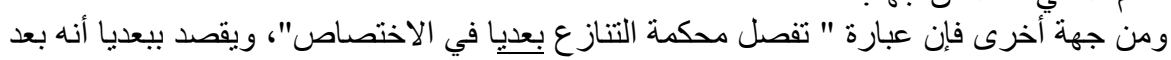

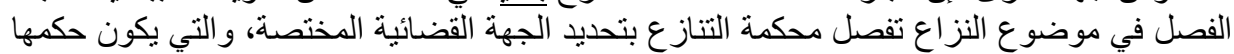

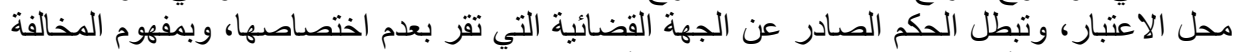

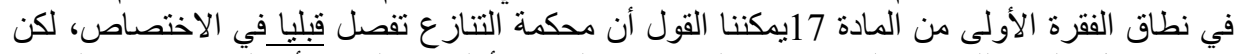

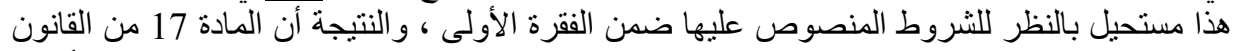
العضوي تجعل التنازع الإيجابي- بموجب الثروط التي تنص عليها- يوصلنا الثنا إلى حالة تناقض في أحكام

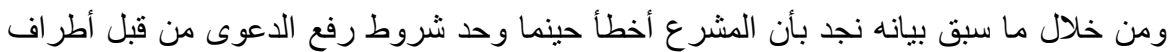

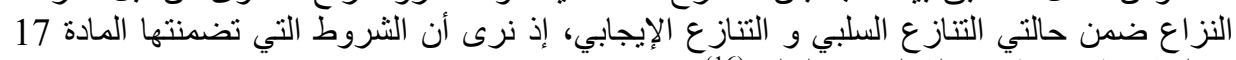

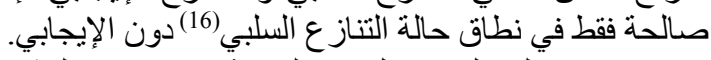

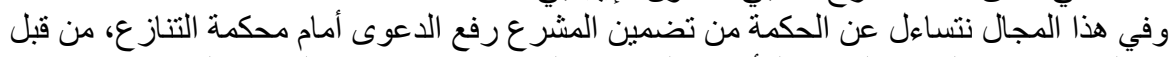

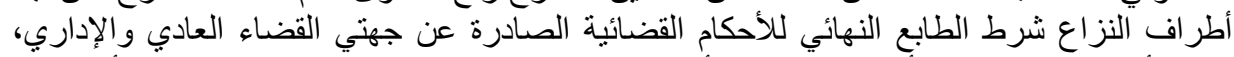

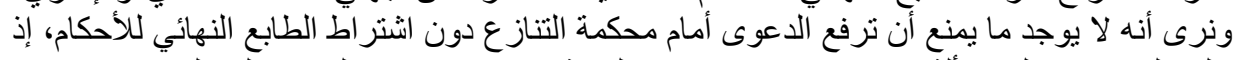

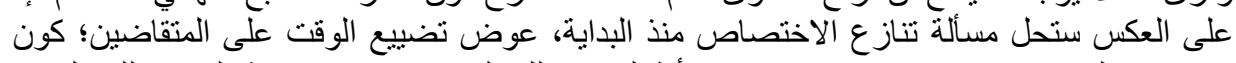

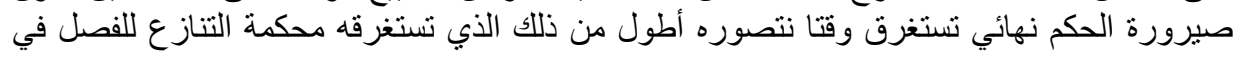

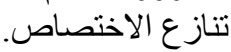

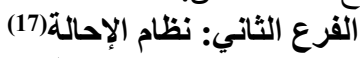

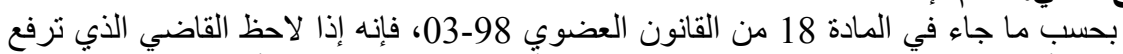

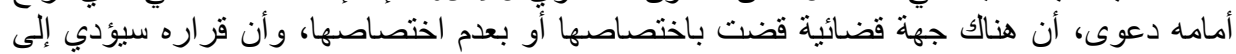

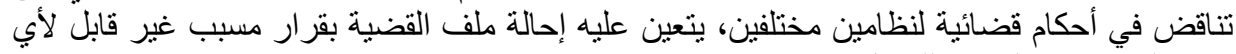

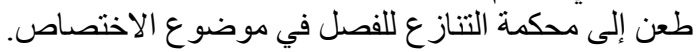

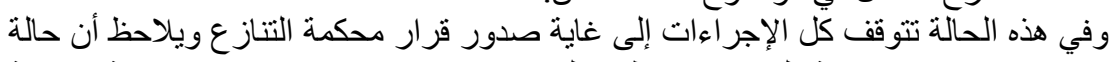

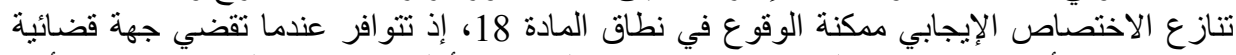
باختصاصها وأصدرت قرار ها القضائي، ويعيد رافع الدعوى الأولى رفع نفس النزاع النّاع مرة ثانية أمام 


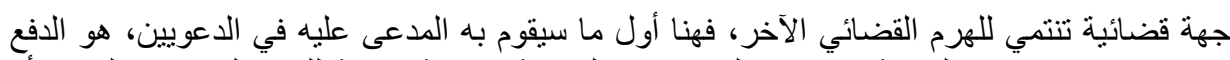

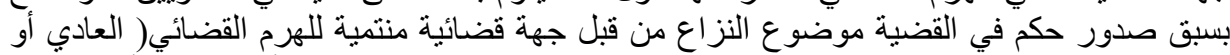

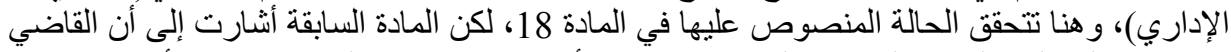

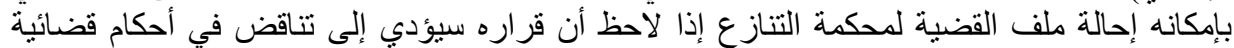

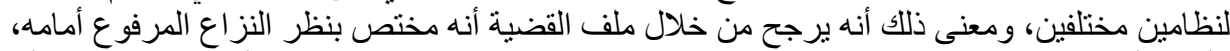

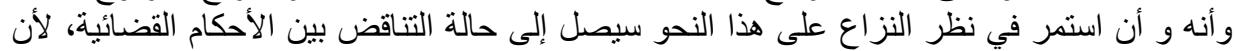

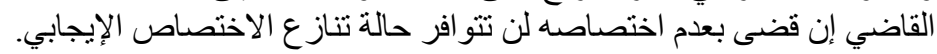

ومما سبق يتبين لنا أن حالة تنازع الاختصاص الإيجابي في نطاق القانون العضوي 98-03

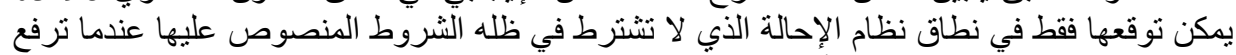

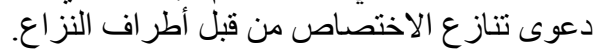

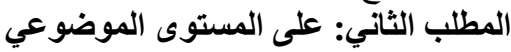

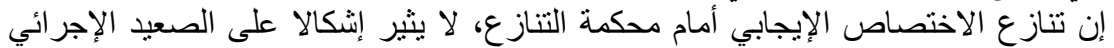

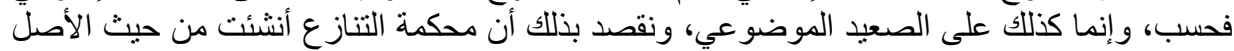

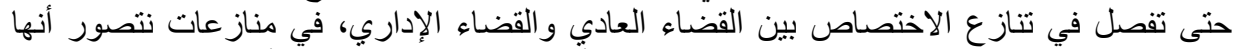

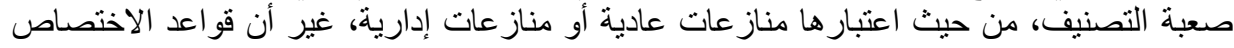

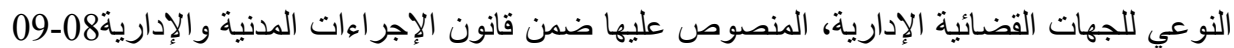

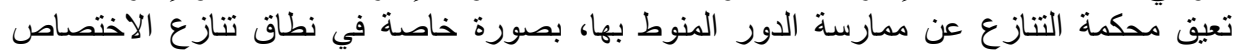
الإيجابي: الأول . مدى تأثثر المعيار العضوي على تناز ع الاختصاص الإسحابي

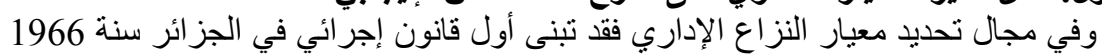

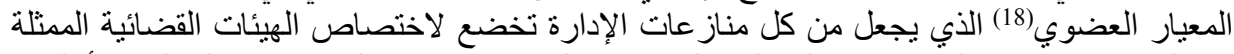

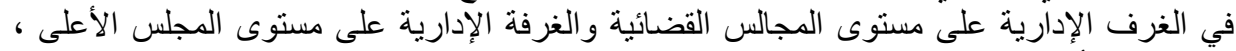

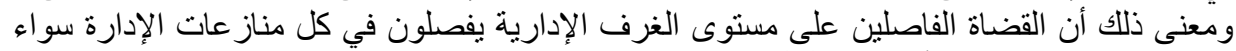

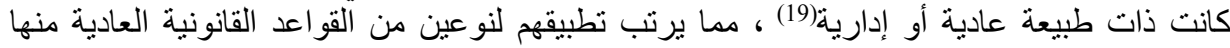

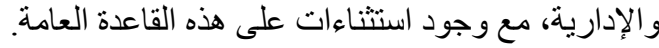

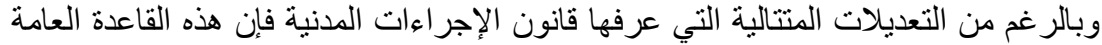

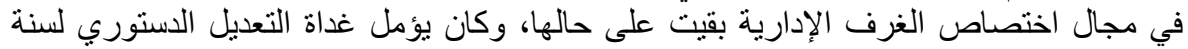

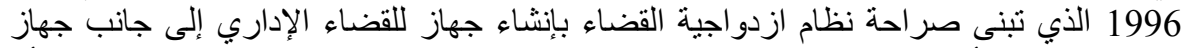

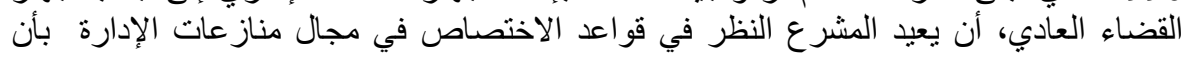

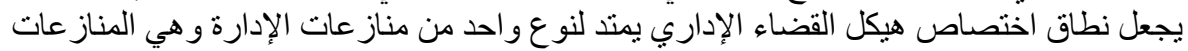

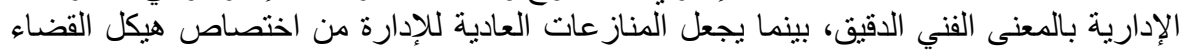

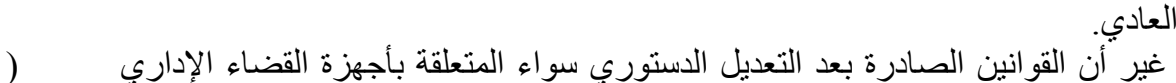

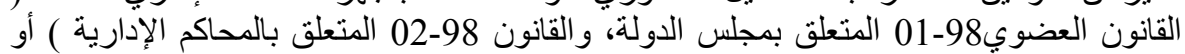

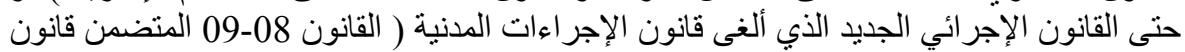

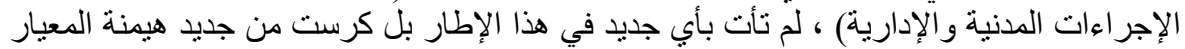

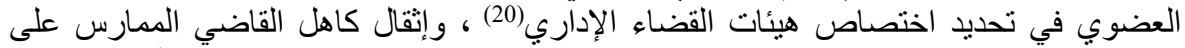

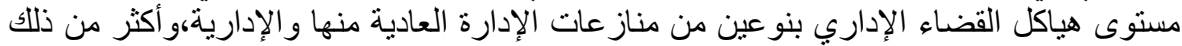
أفرز تبني المشرع للمعيار العضوي عدة مشاكل على المستوى العملي من (21). 
وعليه لا يمكننا الحديث عن نزاع إداري بالمعنى الدقيق والددلول الفني للمصطلح، في نطاق

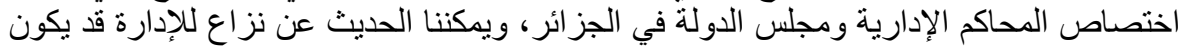

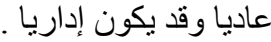

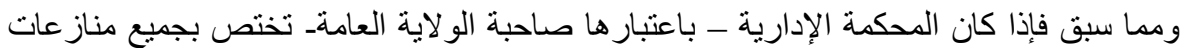

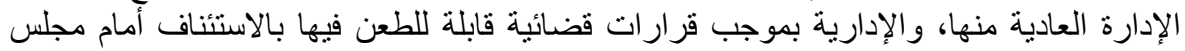

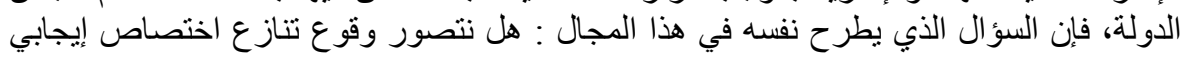

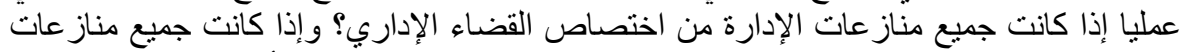

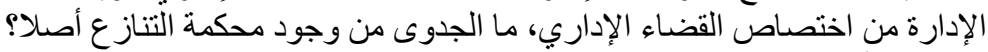

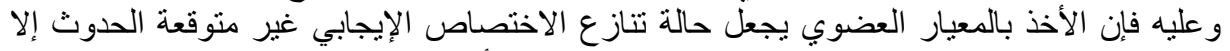

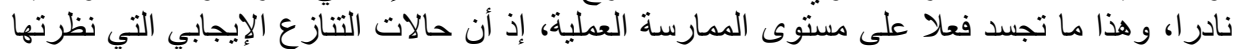
محكمة التتازع تكاد تكون نادرة، وتطغى عليها حالات التتازع علية السلبي.

الفرع الثاني: الاستثناءات الواردة على المعيار العضوي والتنازع الإيجابي

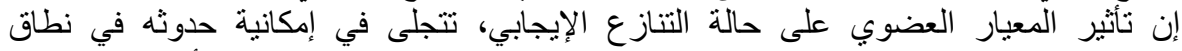

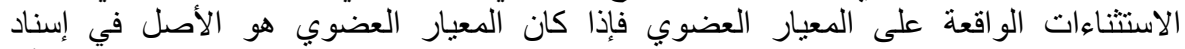

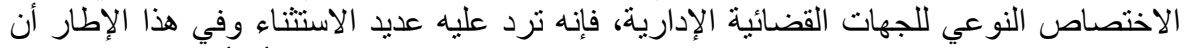

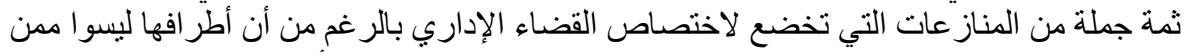

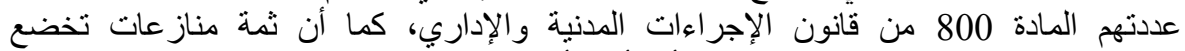

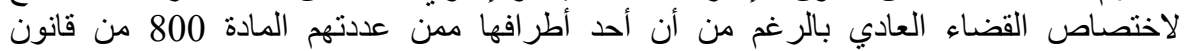

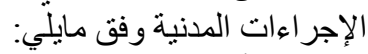
الفقرة الأولى: المنازعات التي ينظرها القضاء الإداري دون أن تكون الإدارة العامة

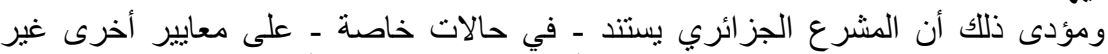

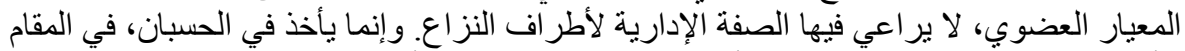

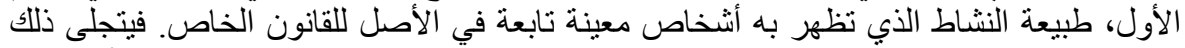

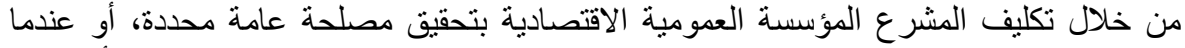

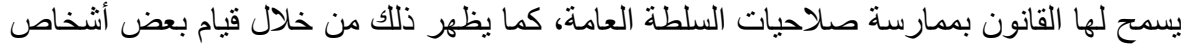

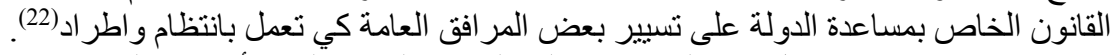

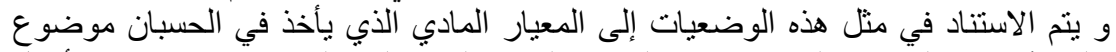

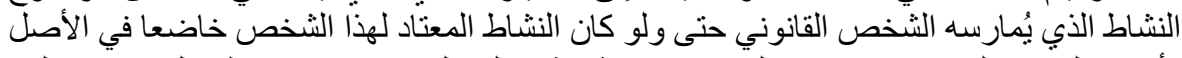

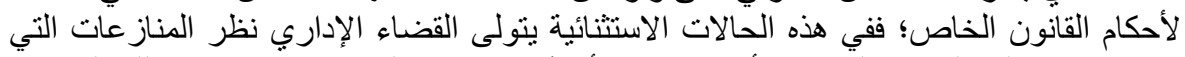

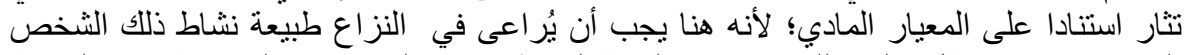

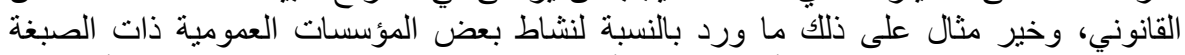

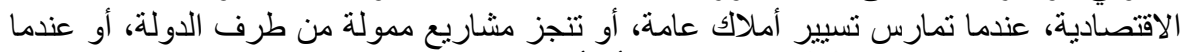

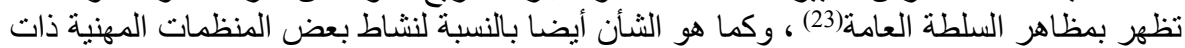

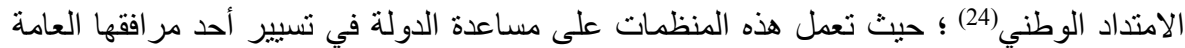
مثل مرفق القضاء وتختص ببعض مناز عاتها جهات القضاء الإداري.

الفقرة الثانية المنازعات التي ينظرها القضاء العادي رغم أن الإدارة العامة طرف فيها

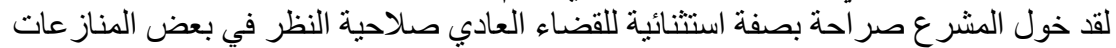

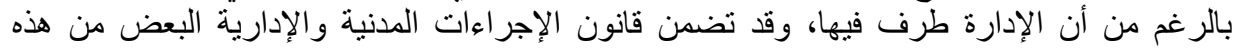

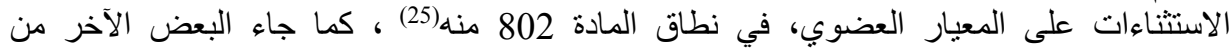




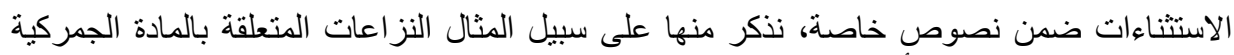

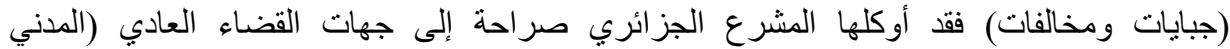

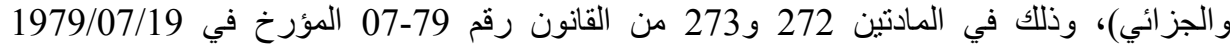
المتضمن قانون الجمارك، المعدل و المتيم (26).

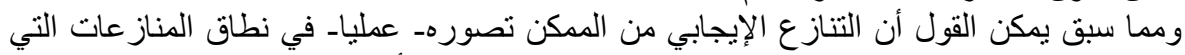

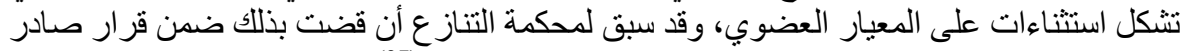

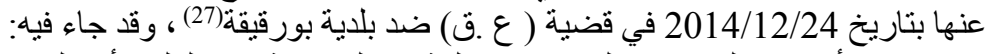

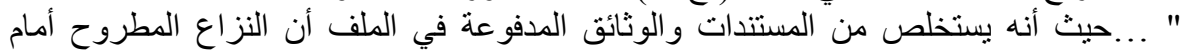

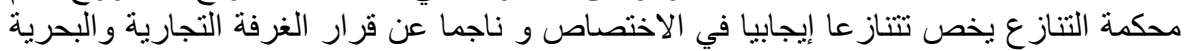

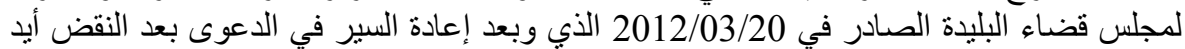

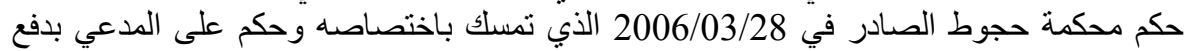

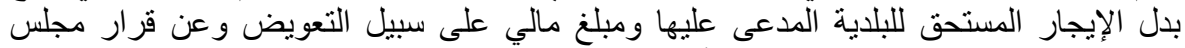

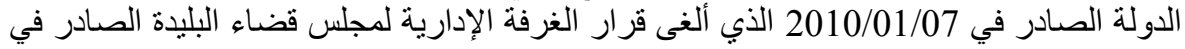

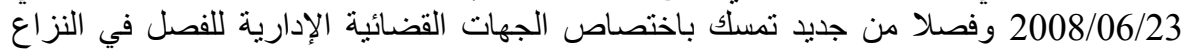

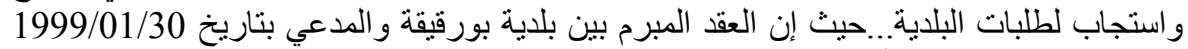

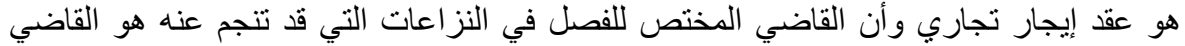

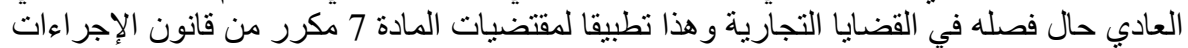

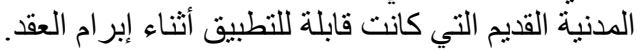

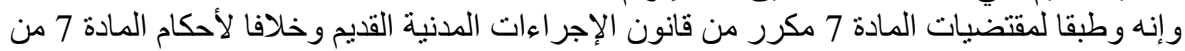

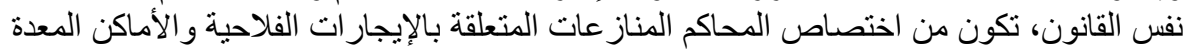

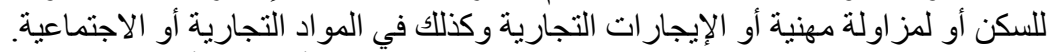

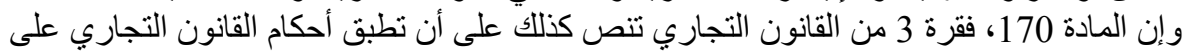

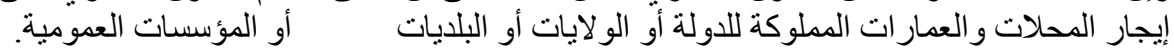
حيث أن مجلس الدولة ألغى، عن خطأ، قرار الغرفة الإدارية لمجلس قضاء الباء البليدة الصادر بتاريخ 2008/06/23

و إنه يتعين بالتالي القول بأن قراره الصادر في 2010/01/07( تحت رقم

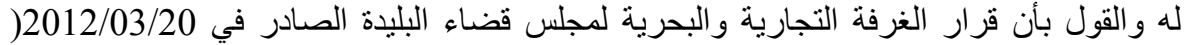
تحت رقم 2012/5563) هو الو اجب التنفيذ...".

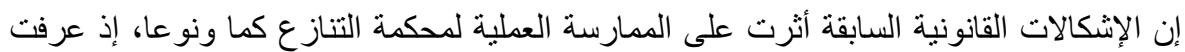

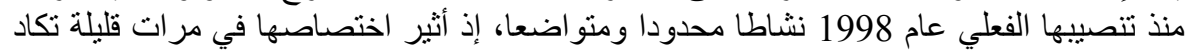

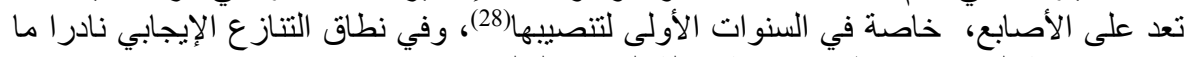

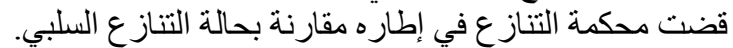

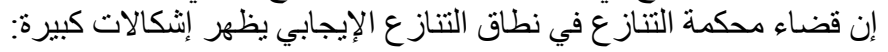

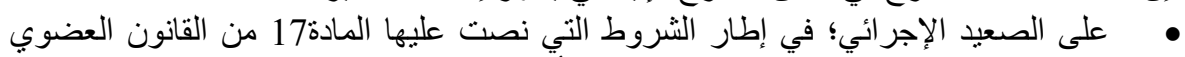

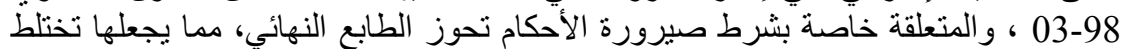

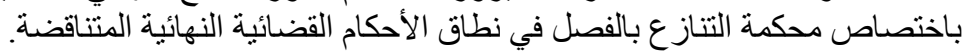
وبالنتيجة فحالة تتازع الاختصاص الإيجابي من الممكن توقعها فقط في نطاق آلية الإحالة وفق المالية المادة 18 من القانون العضوي 98-03. 


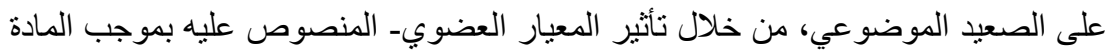

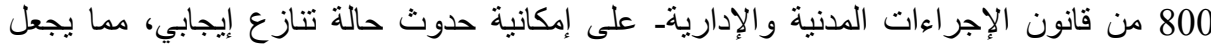

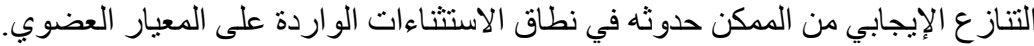

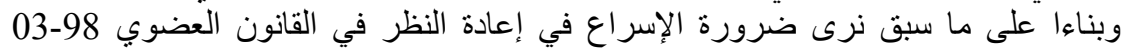

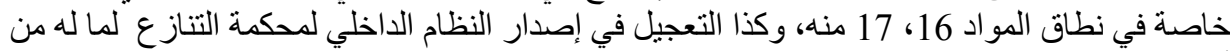

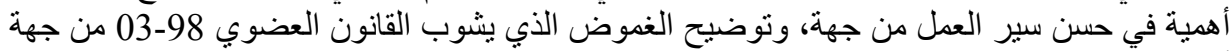

(1)- دستور الجمهورية الجزائرية الديمقراطية الثعبية لسنة 1996، ج.ر.عدد:76المؤرخة في 08

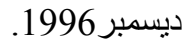

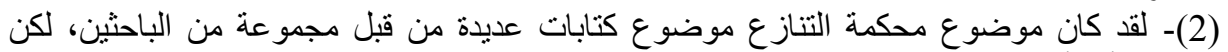

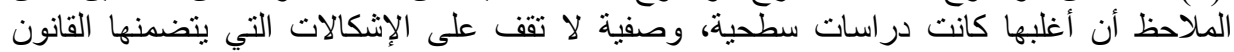

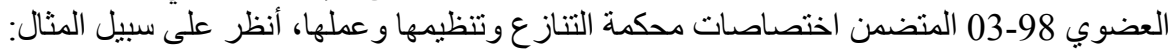

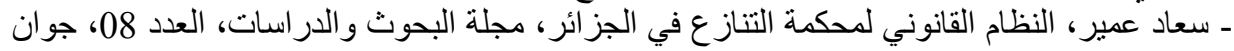
2009،جامعة الو ادي، ص صنام الفاني 101 وما بلئها.

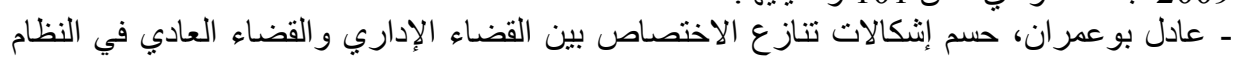
القانوني الجزائري، مجلة دفاتر السياسة والقانون، العدد 08، جانفي 2013، جامعة قاصدي مرباح، الإداء

(3)- القانون العضوي رقم 98-03 مؤرخ في 3 يو نيون سنة سنة 1998، يتعلق باختصاصات محكمة التنازع

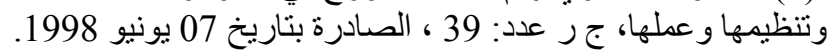

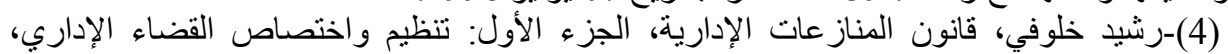

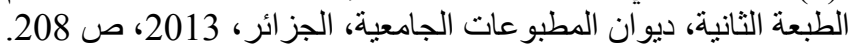

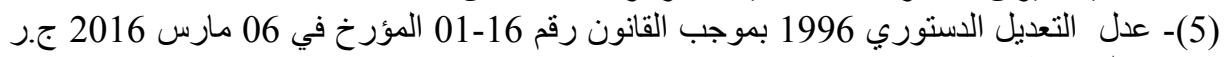

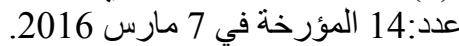
(6)- أصبح رقم المادة السابقة 171 ضمن صنمن التعديل الدستوري 2016.

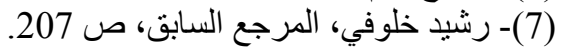

(8) Bernard Pacteau, contentieux administrative,7eme édition, Refondue, P.U.F, Droit, p 192.

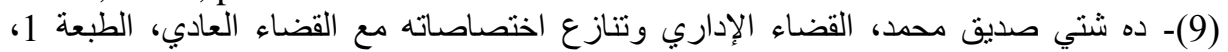

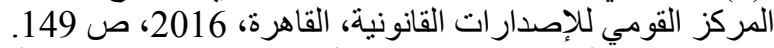

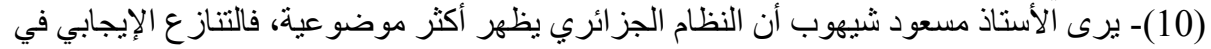

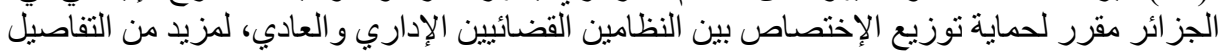
راجع: ـ مسعود شيهوب، المبادئ العامة للمناز عات الإدارية، الجزء الثاني: نظرية الاختصاص، الطبعة 06،

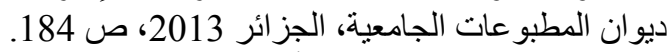

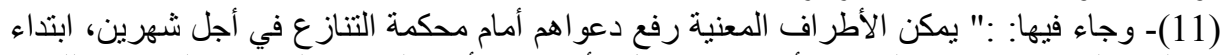

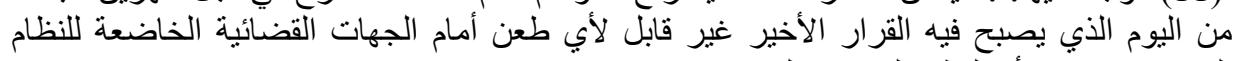
القضائي الإداري أو النظام القضائي العادي...". (12)- تثير الكثير من المراجع إلى التنازع الإيجابي دون الخوض في مدى إمكانية تحقق شروطه

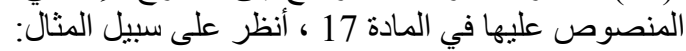
- عصدت عبد المجيد بكر، مجلس الدولة، دار الكتب العلمية، بيروت، لبنان، 2011، ص 285. 
(13)- مجلة المحكمة العليا، عدد خاص، 2009، صاص، صن 73 (14)

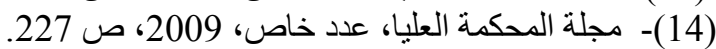

(15)- أثارت الباحثة آمال عباس إلى أنها تحوز معلومات مات من مصادر مقربة من رئيس محكمة التنازع

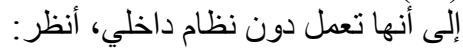

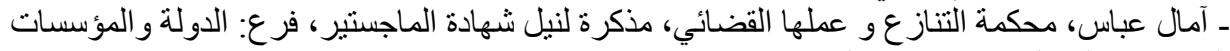

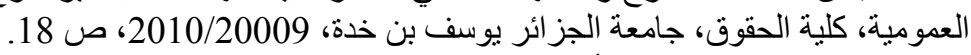
(16)- التنازع السلبي: يعرف بأنه التناز ع الناتج عن تصريح القضاء التهاء الإداري و القضاء العدلي بعدم

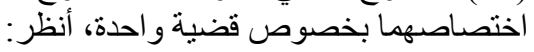

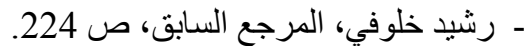

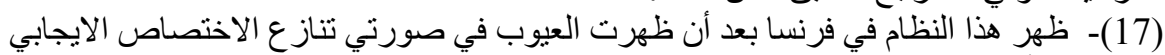

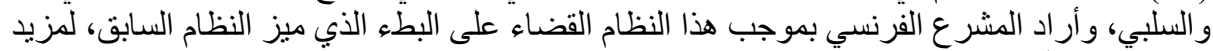

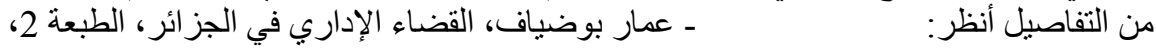

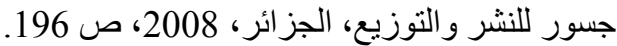
(18)- لمزيد من التفاصيل حول المعيار العضوي كمعيار محدد لاختصاص الجهات القضائية في

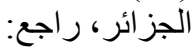

- Mokhtar BOUABDELLAH, L'expérience algérienne du contentieux“ administratif“, Etude critique, Thèse, pour le Doctorat d'Etat en Droit, 13 décembre 2005, FACULTE DE DROIT,_Université des frères MENTOURI Constantine, Algérie 96 et suite.

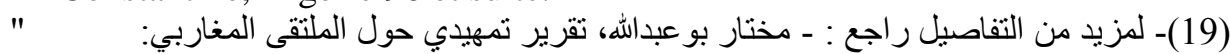

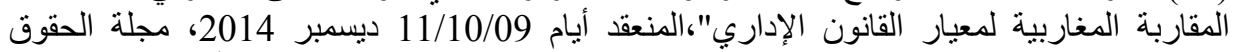

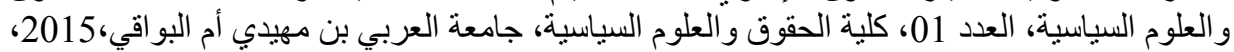
ص 17.

(20)- محمد زغداوي، مدى تماثي المعيار العضوي مع استقلالية المنازعة الإدارية في ظل الإنل

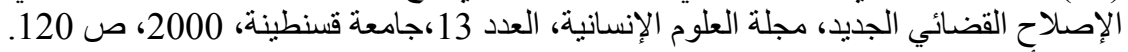
: (21) ـ مر اد بدران، تحديد اختصاص القضاء الإداري: دور المشرع أم دور القاضي؟؟، الملتقى المغاربي:"

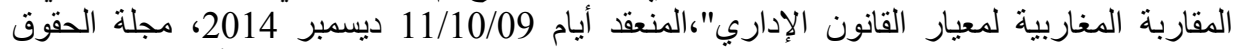

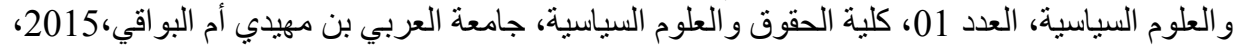
ص و 108 وما بعدها.

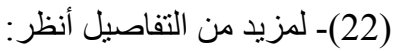

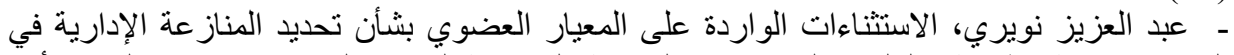

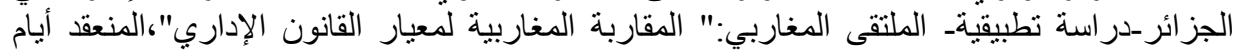

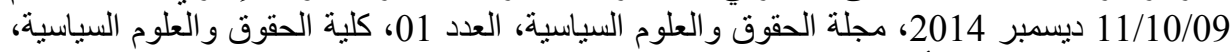

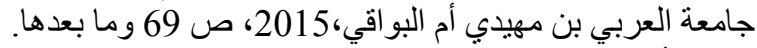

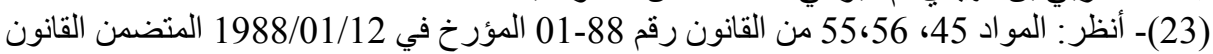

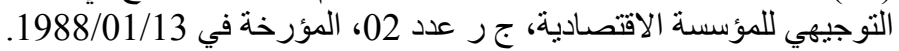

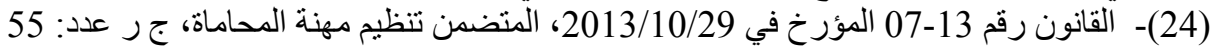

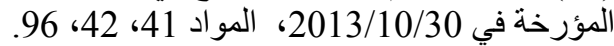
ـ القانون رقم 2006/02/20 206-06 المؤرخ المتضمن تنظيم مهنة المحضر القضائي، ج ر عدد: 14، المؤرخة في 2006/03/08، المون في المادة 56. 
(25)- جاء في المادة 802 من قانون الإجر اءات المدنية والإدارية:" خلافا لأحكام المادتين 800، 801 أعلاه، يكون من اختصاص المحاكم العادة العادية المناز عات الآتية:

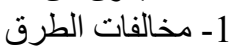

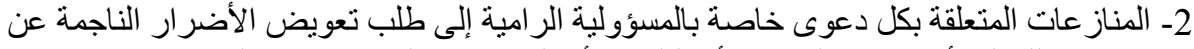

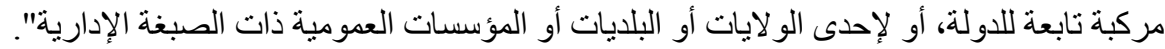

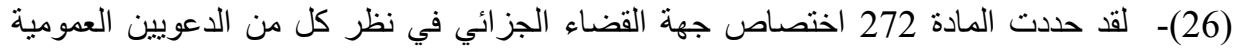

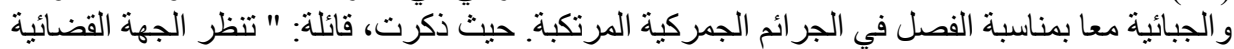

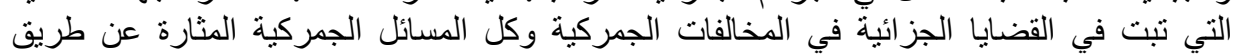
استثنائي. وتنظر أيضا في المخالفات الجمركية المقرونة أو التابعة أو المرتبطة بجنحة من التصاص التصاص

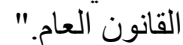

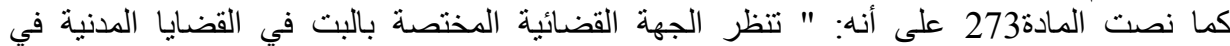

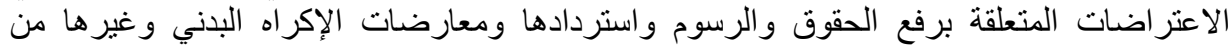

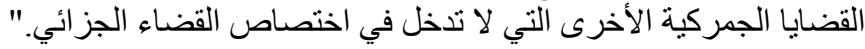

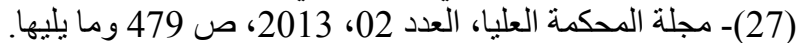
(28)- حول عدد القرار ات التي صدرت عن محكمة التناز ع ونو عها، بصورة خاصة في في بداية ممارستها

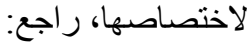

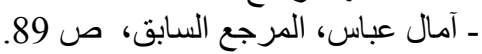

